\title{
Claire Frost
}

Programme Officer, Commonwealth Local Government Forum

\section{Basic Services for All in an Urbanizing World: GOLD III}

David Satterwaite, Routledge, Abingdon 2014

http://www.uclg.org/en/issues/access-basic-services-gold-iii-report

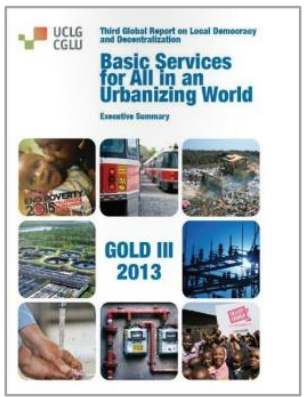

Basic Services for All in an Urbanizing World is the third instalment in United Cities and Local Government's (UCLG) flagship series of global reports on local democracy and decentralisation (GOLD III). In the context of rapid urbanisation, climate change and economic uncertainty the report is an impressive attempt to analyse local government's role in the provision of basic services, the challenges they are facing, and make recommendations to improve local government's ability to ensure access for all. Published in 2014, the report is well positioned to feed into the current debate on what will follow the UN Millennium Development Goals, and examines the role of local government in the provision of basic services across the world regions.

As the responsibilities of local government vary widely, the report has chosen to focus on the five basic services which form the backbone local government of service provision, those that all other services rely on to function adequately; water provision, sanitation, waste management, energy and transport. However the report also provides scope for specific priorities to be reflected in the regional chapters, so the Asia Pacific chapters looks at slum upgrading and climate change adaption, the Eurasia chapter considers public heating, Latin America includes security, and North America looks at internet coverage, as does Europe which also includes an analysis of early childhood and elderly care.

The report reviews issues of access, legal and institutional frameworks, service management and financing, and governance structures. It works to strike a balance between the presentation of global and national level data, and local level case studies. Of course one of the limitations of the report, is that in taking a global approach to the subject matter there is very little space to go in-depth on the complex conditions found within countries, or the very real differences between different local governments in and between countries. However this does not reduce the achievement of the report. In the presentation of its global overview and central arguments GOLD III is compelling in its call for strengthening the capacity of local government to plan, finance and manage service provision. 
Especially forceful are some of the statistics presented to illustrate the size of the infrastructure deficit (between US\$43-53billion annually in Africa) or the coming investment needed (US\$10trillion over the next ten years in Asia). Exponential urban growth is putting unprecedented pressure on urban areas, and lack of data and planning capacity at the local level is presented as a time bomb throughout the report, but is especially highlighted in Africa and Asia where the majority of this century's urbanisation will take place. In this context the report is a strong reminder that we cannot overlook the mechanisms of implementation in the new set of global development goals. As GOLD III clearly concludes, local government will be at the forefront of implementing the Post-2015 development agenda and as such must be enabled to meet its basic service delivery responsibilities as these are the foundation on which all social, economic and environmental outcomes are based. 